\title{
Uma etnografia política de fio de teNsão
}

\author{
Ítalo de Melo Ramalho ${ }^{1}$ \\ http://lattes.cnpq.br/2140107403563901
}

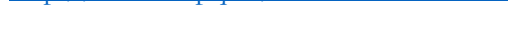

Fernanda Santos ${ }^{2}$

http://lattes.cnpq.br/6242769486692920

Enviado em: 29/08/2018

Aceito em: 23/11/2018

\section{Introdução}

Christina Ramalho é uma autora brasileira que se locomove muito bem pelos diversos gêneros literários. Do romance (ainda inédito) ao conto. Do ensaio ao texto acadêmico como complementação da sua atividade de docente e pesquisadora da Universidade Federal de Sergipe. Da crítica ao teatro. Da prosa à poesia (COELHO, 2002, p. 123-125).

Nossa leitura crítica será dedicada à obra poética fio de teNsão, que comentaremos em seguida. Antes, é necessário informar que Ramalho é autora de seis títulos de poesia, sendo o primeiro, Musa carmesim (1998), que é um poema épico, e por isso já deixa marcado, logo na estreia, que é uma poeta de fôlego. As publicações subsequentes no campo da poesia seguem com o lirismo de Laço e nó (2000), e os mais recentes e não menos líricos fio de teNsão (2017), Ítalo (2018, e-book), Lição de voar (2019, e-book) e Poemas minimos (2019, e-book).

É bom que se diga que a poeta não encerra suas atividades artísticas apenas na literatura. Ela de fato vive com afinco o fazer poético em sentido lato, estendendo suas agruras e inquietações para a pintura, a música e a colagem em madeira e cerâmica. Christina vive intensamente a arte. E essa vivência remete ao pensamento de um grande brasileiro, Ariano Suassuna, que dizia que "a literatura é uma espécie de protesto contra a morte". Vê-se que a frase dita por Suassuna e repetida em entrevistas como a que deu ao jornalista Gerson Camarotti do portal G1, explicita que o papel do/da artista na sociedade tem a mesma função do radar, capta tanto as mais intensas, como as mais inaudíveis ondas sonoras da atmosfera social, de forma que, abastecido com essa matéria fina ou bruta, visível ou invisível, o/a poeta burile a imagem captada de maneira que plasme com a fibra da palavra e da beleza o retrato do seu tempo. O/A poeta também tem como função a de ser antena que, sincronicamente com a captação, retransmite, depois de lapidada leitura, a perfeição hostil do mundo agora transformada em perfeição estética e vida. E aqui, utilizando a licença poética e ensaística, ampliamos o aforismo de forma que enquadramos a poeta e a sua pluridiversidade artística, refazendo a máxima da seguinte maneira: a arte da autora é uma espécie de protesto contra a morte da ética e da estética nas gentes. E é a respeito dessa poeta que brevemente falamos, dando especial atenção para o mais recente canto novo por ela publicado fora dos muros da virtualidade: fio de teNsão.

\footnotetext{
${ }^{1}$ Advogado. Mestrando do Programa de Pós-Graduação em Antropologia da Universidade Federal de Sergipe. Email: talodemeloramalho@gmail.com.

2 Vice-Coordenadora do Programa de Pós-Graduação em Letras, da Universidade Federal do Amapá (PPGLET). Professora Adjunta no colegiado de Letras da Universidade Federal do Amapá/Campus Santana. Doutora em Letras pela Universidade Federal do Espírito Santo. Doutora em História pela Universidade Federal de Santa Catarina. Email: fercris77@gmail.com.
} 


\section{1. fio de TeNsão, o livro}

Conforme referido, a obra sobre o qual debruçaremos a análise é fio de teNsão. A obra veste o manto da saudade. Mais especialmente da saudade viva. A saudade que conservamos nos nossos corações como representação da esperança. A saudade que a cada esquina vencida estará de braços ou portas abertas para o acolhimento das nossas ansiedades. Ansiedades que se revelam pela busca incessante da vida real e de viés. Ramalho, no decorrer do livro, vasculha cada armário, cada pessoa, cada recanto, como sendo ela própria ou como fazendo ser a sua palavra a palavra do/da seu/sua leitor/a. Palavra que, como uma roupa que sangra e que veste a sua própria carne, se transfigura em palavra-pele. Aqui a poeta socializa a sua realidade particular alcançando no seu semelhante uma armadura de derme, carne e sangue, composta com a mesma substância mineral que a sua. Vestimenta essa que correrá por todo o discurso poético do livro. Senão vejamos:

$$
\begin{gathered}
\text { É pele } \\
\text { Ando vestida } \\
\text { de saudade viva. } \\
\text { Cada roupa } \\
\text { é um recanto, } \\
\text { um momento. } \\
\text { Se tiro a roupa, } \\
\text { a carne sangra. } \\
\text { Não é roupa. } \\
\text { É pele. } \\
\text { (2017, p. 18) }
\end{gathered}
$$

O livro fio de TeNsão, a partir do olhar lançado, está estruturalmente dividido em três cantos. Dividimos em cantos por uma questão não apenas de recortar e separar a matéria de análise, mas também de evocar homenagens aos/às bardos/as da poesia épica tão caros à poeta e pesquisadora desse gênero literário. O canto I traz o título de Temporal; o canto II Ilha; e o canto III Bonança. A ótica etnográfica será voltada para o primeiro canto, intitulado Temporal.

\section{O tempo do outro (Etnografia estética e política)}

Como o próprio título sugere, a "teNsão" é um marcador cronológico da vida contemporânea do Brasil. O tempo realmente anda deveras esquisito abaixo do Equador. Não podia ser diferente para quem tem a sensibilidade como uma antena captadora dessas ondas, manifestar-se alheiamente aos acontecimentos políticos e sociais que se sucedem. Seria irresponsabilidade ou silenciamento por morte ou mordaça. Como disse o fotógrafo brasileiro Sebastião Salgado: “O Brasil está doente!” E a poeta, graças à sensibilidade, não se silenciou diante da hecatombe em movimento constante e uniforme que se anunciava e gritou:

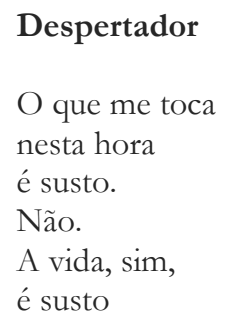

sem botão para apertar 


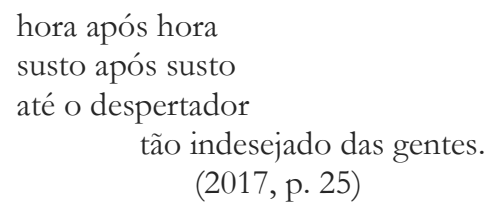

É sabido que o ser humano vem se inventando e reinventando constantemente. As reinvenções são paráfrases do dado e do construído. Se entendermos por dado coisas que escapam à criação humana e que ocupam e dividem o mesmo lugar de sujeito com todos que compõem o fluxo de materiais, chamaremos isso de natureza. Natureza aqui não ganha o sentido de oposição ou de qualquer outro que a descole do ser humano. Natureza e ser humano são recíprocos e, por isso, se fundem em peças que perpassam e permeiamse independentemente do gosto alheio. E aqui marco a minha fala com uma brevíssima citação do escocês Tim Ingold: "a vida não é estática e acabada; ela é dinâmica e criativa" (2012, p. 27).

Quando se reinventa, está subentendido que existe ou existiu um ponto de partida para tal. Nesse sentido, pode se tomar uma cadeira como exemplo. Depois que o conceito abstrato da cadeira foi retirado do mundo perfeito das ideias e passou a ocupar fisicamente o mundo imperfeito e mal-acabado da realidade, a cadeira passou a ser um objeto de constante reinvenção. As invenções parecem-me que guardam semelhança em alguns aspectos com as reinvenções, mas aquelas destinam-se a ir mais adiante, porque o sentido de inventar agrega o valor do ineditismo; do espetacular; do superpoder; do super ser-humano. Estas percepções, de alguma maneira, estão ligadas ao campo do sagrado e, portanto, do inexplicável. Estes traços fazem do inventor um gênio incompreendido.

A poesia ocupa justamente o espaço deixado entre a invenção e a reinvenção. Metaforicamente ela está localizada entre a derme da reinvenção e o músculo da invenção. Ela é o tutano do osso, como também é o óleo que lubrifica a cartilagem por trás da rótula do joelho. É o fluido que desliza pelos espaços mais inóspitos com a capacidade de resilir, conforme a forma e a deformação da célula. A poesia só é possível devido às experiências que transformam as vidas socioindividualizadas por meio da criação que vai muito além da invenção e da reinvenção. Como disse Maximiliano Torres, em artigo sobre as novas vozes da poesia feminina carioca, dentre as quais figura a poeta Christina Ramalho:

[...] é a poesia, criação, aquele que dá existência ao que não existe; é criação de beleza segundo o corpo e o espírito; é um desejo de procriação do belo, e a procriação, por perdurar, significa, para o mortal, a imortalidade (TORRES, 2004, p. 208).

Muito já se escreveu sobre estética. Mas não poderíamos deixar de suscitar rapidamente sobre ela a estética como base da beleza artística. Como também a política por ora manifestada na poesia de Christina Ramalho, através de um discurso que representa uma parcela significativa da coletividade.

Todo iniciado na matéria antropológica tem conhecimento de que o estudo das relações é ponto central para a disciplina. Observar as relações dentro do jogo da vida é o que motivará o/a pesquisador/a a se debruçar sobre o objeto da análise. Munido da teoria antropológica do tempo de Johannes Fabian e o seu método de observação etnográfica, descubro que o antropólogo traz ao debate duas vertentes do tempo etnográfico que pareceram bastante satisfatórias para observar o canto Temporal: o tempo denotativo e o tempo conotativo. Através dos sentidos denotativo e conotativo é que emendarei minha análise ao sentido estético e político. 
Por denotação compreende-se que é o sentido literal do termo. Ou seja: aquilo que é descrito como uma coisa que não tem valoração significativa fora daquela descrição semântica. Já o sentido conotativo é entendido como uma forma mais maleável e plurissignificativa das palavras. Tem uma ligação sem rodeios com a imagem. Esse diálogo entre a dureza e a elasticidade das palavras, dos sons e das imagens, é o que transforma a hostilidade da vida em um espaço/tempo mais ameno para viver. E quem tem esta habilidade para ler as entrelinhas a ponto de abstrair para criar e o poeta. Por este motivo, os criadores e as criadoras, cabe dizer, estarão sempre entre os mais requisitados, por serem os que melhor grafaram e grafam, quando se quer observar civilizações mais antigas ou contemporâneas. Uma volta pelos museus ou casas dos saberes como universidades, bibliotecas, centros culturais e outros afins, nos permite perceber a sua importância. Por exemplo: o que seria da Espanha sem a genialidade de Miguel de Cervantes? Quixote é uma obra que extrapola o seu tempo e que canta, através do riso, a sociedade e o indivíduo castelhano. Cervantes, sem perder o fio da sua pena, falou de política quando condecorou Sancho como governador da ilha; e falou de estética quando subverteu a coisa denotativa dos moinhos de ventos em conotativos gigantes de pedra. Essa transfiguração dos objetos e dos sujeitos é o que escapole da linguagem convencional e aporta na linguagem filosófica do belo.

Na observação de campo, o canto Temporal do fio de tensão tem duas realidades colocadas em pauta pela poeta: a real e substantiva e a aparente e adjetiva. Assim, procuramos traçar um paralelo entre a observação da coetaneidade e do alocronismo (FABIAN, 2013, p. 103) do discurso antropológico. Aqui são apresentadas duas categorias que sustentam o fazer antropológico que perpassam a pesquisa e a produção da sua literatura.

A coetaneidade/contemporaneidade etnográfica demonstra que fio de tensão, de fato, pertence ao seu tempo. Palavras como "meritocracia", "vagabundos", "vandalos", "ideologia" e "hipocrisia" marcam a existência do presente político/social na sociedade brasileira.

O alocronismo, por sua vez, como uma categoria da realidade feita a partir de uma leitura temporal do objeto, evoca uma distância entre o trabalho de campo e o gabinete, ocultando os paradoxos temporais para subvertê-los em uma espécie de monólogo etnográfico. Porém, para etnografar os poemas do canto "Temporal", foi preciso experienciar não apenas uma vivência íntima com os versos, mas também um compartilhamento recíproco do tempo entre sujeito e objeto; por isso, uma leitura antropológica de poesia exige uma observação do tempo histórico que está impregnado no tempo literário. Como diz Fabian,

[...] A pesquisa empírica produtiva, acreditamos, é possível apenas quando pesquisador e o pesquisado compartilham o Tempo. Somente como práxis comunicativa a etnografia realiza a promessa de gerar um novo conhecimento sobre uma outra cultura. No entanto, o discurso que pretende interpretar, analisar e transmitir o conhecimento etnográfico à sociedade do pesquisador é pronunciado a "distância”, isto é, a partir de uma posição que nega a coetaneidade ao objeto da investigação (FABIAN, 2013, p. 100).

Exercitando o olhar crítico etnográfico, não tivemos preocupações em nos distanciar do objeto, pois, apenas com a proximidade quase siamesa dele, é que poderíamos não perder o vínculo temporal da coetaneidade entre o objeto e o sujeito. Dessa maneira, a imersão na poesia do canto Temporal só reafirma que o que ali está poetizado também está substancializado e adjetivado pelo tempo etnográfico.

Os versos do poema "O que me cansa", a poeta grita para uma realidade que se desenha no horizonte, responsabilizando a cegueira dos homens de se medirem 
constantemente em estatísticas que apresentam uma concorrência ao topo da pirâmide:

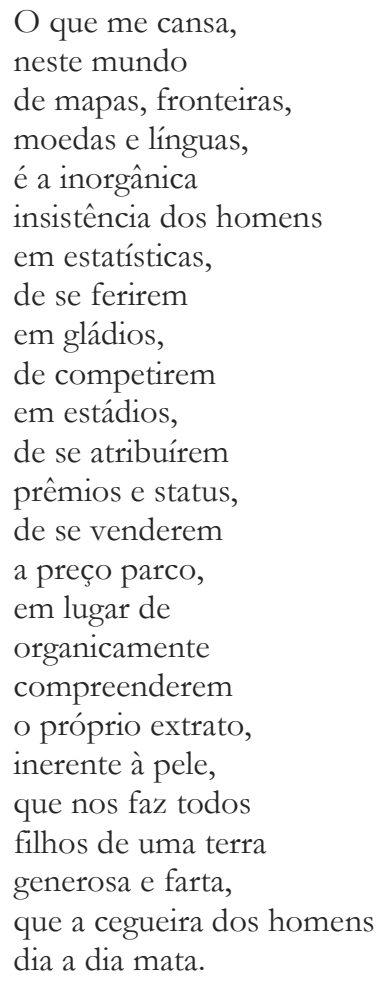

(2017, p. 23)

Eles, os homens, terminam por fechar os olhos por ouvir o hipnótico canto do deus mercado. O "extrato inerente à pele" é o lugar de onde eles fogem, ou do qual se desviam. A poeta marca, assim, a necessidade de uma reflexão profunda dos homens sobre Si mesmos e sobre o mundo.

\section{Referências}

INGOLD, Tim. Trazendo as coisas de volta à vida: emaranhados criativos num mundo de materiais. In: Horizontes Antropológicos, Porto Alegre, ano 18 n. 37, p. 25-34, jan/jun. 2012

COELHO, Nelly Novaes. Dicionário crítico de escritoras brasileiras: (1711-2001). São Paulo: Escrituras editora, 2002.

FABIAN, Johannes. O tempo e o outro: como a antropologia estabelece seu objeto. Petrópolis, RJ: Vozes, 2013.

RAMALHO, Christina. fio de teNsão. São Paulo: Benfazeja, 2017.

RAMALHO, Christina. Musa Carmesim. Campos do Jordão: Vertente, 1998.

RAMALHO, Christina. Laço e Nó. Rio de Janeiro: Elo, 2000.

RAMALHO, Christina. Lição de voar. Natal: LucGraf, 2019. Disponível em:

https://docs.wixstatic.com/ugd/e6676e_7e568a513b4846108cd152dc6d39c49f.pdf. Consultado a 10/03/2019.

RAMALHO, Christina. Poemas mínimos. Natal: LucGraf, 2019. Disponível em: https://docs.wixstatic.com/ugd/e6676e_19f1bfed5259424282b5c389e2209e8a.pdf. Consultado a 10/03/2019. 
SUASSUNA, Ariano. https://epoca.globo.com/vida/noticia/2014/07/arte-euma-especie-de-bprotesto-contra-morteb.html. Consultado a 10/03/2019.

TORRES, Maxmiliano. As incursões de Eros no cenário da poesia carioca contemporânea: Christina Ramalho, Paula Glenadel, Sylvia Cyntrão, Ângela Montez, Ângela Maria Carrocino, Maria Dolores Wanderley, Denisis Trindade. In: CUNHA, Helena Parente (org). Além do cânone: vozes femininas cariocas estreantes na poesia dos anos 90. Rio de Janeiro: Tempo brasileiro, 2004. 